\section{ADRENAL AUTOGRAFTS IN TREATMENT OF CUSHING'S DISEASE}

BY

\author{
H. K. IBBERTSON, M.R.C.P., M.R.A.C.P.* \\ Medical Tutor
}

AND

\section{K. P. O'BRIEN, M.R.A.C.P. Medical Registrar}

From the Auokland Public Hospital, Auckland, New Zealand

The accepted treatment for Cushing's syndrome caused by benign or malignant neoplasms of the adrenal cortex is unilateral adrenalectomy with conservation of the contralateral gland (Sprague, 1953). There is less agreement, however, on the correct therapy for the majority of patients with this condition, whose syndrome is due to bilateral adrenal hyperplasia. Cushing (1932) envisaged a primary pituitary disorder, and early reports of deep radiotherapy to the pituitary gland were encouraging (Luft, 1946 ; Skrimshire, 1955). Subsequent experience proved less successful (Plotz et al., 1952 ; Cope and Raker, 1955), a clinical remission occurring in only one-quarter of the patients treated.

More patients obtained remission after subtotal adrenalectomy (Sprague, 1953 ; Bishop et al., 1954) ; the amount of adrenal tissue removed is critical, however, and the incidence of incomplete remission or relapse is appreciable (Lessof and Bishop, 1956). For this reason there has been an increasing tendency to recommend total bilateral adrenalectomy as the definitive therapy (Sprague et al., 1961).

In an attempt to avoid the disadvantage of hormone dependence following this operation, Franksson et al. (1959) described five cases of Cushing's syndrome in which adrenal tissue was implanted into the sartorius muscles at the time of operation. At least three of these patients resumed normal activities without steroid replacement in the post-operative period.

In the present paper two cases of Cushing's syndrome in which adrenal autotransplantation has been performed are described. The first patient was found to have a unilateral adrenal carcinoma and the other had bilateral adrenal hyperplasia.

\section{Methods}

Steroid Estimation.-17-Ketosteroids were estimated by the method of Drekter et al. (1952) and the 17hydroxysteroids by the method of Appleby et al. (1955). To test adrenal responsiveness, urinary steroids were estimated for four days during stimulation with intramuscular zinc corticotrophin 40 units b.i.d., and for three days during and after a 24-hour course of "metopirone," $750 \mathrm{mg}$. six-hourly. In addition, urine steroids were estimated during a six-day course of dexamethasone, $2 \mathrm{mg}$. and $5 \mathrm{mg}$. daily.

Antibody Studies. - The adrenal tissue was frozen at $-20^{\circ} \mathrm{C}$. immediately after removal. An extract was prepared by finely slicing the organ after removal of fat, and homogenizing one part in three parts of physiological satine solution in a Waring blender. The extract was centrifuged at 3,000 r.p.m. and the supernatant used

*Now at Department of Medicine, Royal Free Hospital,
London. as antigen, diluted to eliminate anti-complementary activity. The technique of the complement fixation was that described by Anderson et al. (1957). Tests were performed by incubation at $37^{\circ} \mathrm{C}$. for one hour and overnight at $4^{\circ} \mathrm{C}$. Sera from both patients were tested against antigen prepared from their own and each other's adrenal tissue.

Operative Technique.-Steroid cover was provided in both instances by intramuscular cortisone acetate, $200 \mathrm{mg}$. on the evening before, and on the morning of operation. An intravenous infusion of $100 \mathrm{mg}$. of hydrocortisone hemisuccinate in normal saline was given throughout the operation and continued at a rate of $100 \mathrm{mg}$. six-hourly for the next 24 to 36 hours. Cortisone acetate was subsequently given by mouth and progressively reduced from 200 to $37.5 \mathrm{mg}$. daily over a 10-day period. An anterior abdominal approach was used in each instance. Both adrenals were palpated to exclude tumour, and subsequently removed. Each gland was then sliced into 30 to 40 pieces about $1-2 \mathrm{~mm}$. thick and immediately placed in a Petri dish standing in ice and containing a small amount of normal saline. The fragments were then transferred to separate pockets already prepared by blunt dissection along the middle third of each sartorius muscle. Grafting was completed within 10 minutes of the removal of each adrenal gland.

\section{Case 1}

A 39-year-old labourer whose hypertension was discovered nine years previously, following symptoms of dyspnoea on exertion and ankle swelling. had difficulty in keeping a job because of excessive fatigue, progressive muscular weakness, and irritability. He noticed loss of libido and sexual potency during the same period, and for two or three years had complained of low backache. One year before admission he suffered a crush fracture of a thoracic vertebra following a fall. He was finally admitted to hospital in acute heart failure. Examination showed signs of left ventricular failure and a blood-pressure of $160 / 125$. He had a plethoric moon face. a dorsal kyphosis with truncal obesity, and peripheral wasting. There was acne on the face and neck, with a fine skin and livid striae on the abdomen. The E.C.G. showed marked left ventricular hypertrophy. $X$-ray examination showed moderate cardiac enlargement with pulmonary oedema, multiple old rib fractures, and rarefaction of dorsal and lumbar spine with collapse of the fifth dorsal vertebra. $X$-ray examination of the skull and pituitary fossa showed nothing abnormal. Presacral air insufflation showed excessive perirenal fat with inadequate visualization of the adrenals. Glucosetolerance test: diabetic curve. Glucose-insulin test: normal insulin sensitivity. Serum potassium $3.8 \mathrm{mEq} / 1$. Serum bicarbonate $23 \mathrm{mEq} / \mathrm{l}$. The preoperative urinary steroid values are shown in Table $I$.

Operation.-Following palpation of both adrenals the left gland was removed. After slicing. the fragments were implanted into the sartorius muscle in the left thigh. Later dissection of the right adrenal revealed a $2-\mathrm{cm}$. soft encapsulated tumour which had not been previously detected. This was removed together with the right gland. The histology report on the tumour was: "The tumour is covered with a fine hyaline fibrous tissue capsule and is composed of large polyhedral cells with eosinophilic cytoplasm showing some variation in density. The nuclei show marked variation in size and most are hyperchromatic. The chromatin is finely granular and one or two nucleoli are present. Mitotic figures are not seen. The tumour is very vascular and there is slight invasion of the capsule; carcinoma of the adrenal."

Post-operative progress was uneventful, and the blood. pressure fell to normal within a week of operation. 


\section{Case 2}

A 41-year-old dairy farmer noticed general lassitude and irritability for 16 months before admission. He also had decreased sexual potency and weakness of the limbs. $\mathrm{He}$ developed persistent severe headaches and angina pectoris, and was found to be hypertensive. Fair control of his blood-pressure was obtained with guanethidine over a sixmonth period. At the time of admission to hospital he had a severe cellulitis in the region of the right knee. His mother had died of an adrenal carcinoma some years previously. The clinical picture was less advanced than in Case 1. He had a plethoric moonface but no trunk obesity or striae. There was obvious muscular wasting of the limbs, and multiple bruises were present. The standing bloodpressure on admission was $170 / 110$ (on guanethidine $50 \mathrm{mg}$. daily). He was suspicious and reluctant to undergo investigation. $X$-ray examination of the skull and pituitary fossa revealed nothing abnormal. Presacral air insufflation with tomography showed a normal right adrenal but apparent enlargement of the left adrenal to three times its normal size. Glucose-tolerance test: diabetic curve. Glucoseinsulin tolerance: normal insulin sensitivity. Serum potassium $4.3 \mathrm{mEq} / \mathrm{l}$. Serum bicarbonate $28 \mathrm{mEq} / \mathrm{l}$. The pre-operative urinary steroid values are shown in Table I.

Operation.-Both adrenal glands, which felt normal, were removed intact. The left gland was surrounded by a mass of fat. No accessory adrenal tissue was found and the histology of the excised tissue was normal. After slicing, the fragments were implanted into the sartorius muscle in each thigh.

Post-operative progress was uneventful. The abnormal clinical features had diminished three months after operation but the blood-pressure remained elevated, the guanethidine requirement being unchanged.

\section{Post-operative Studies}

The results of the steroid estimations performed during the post-operative period are shown in Table II. Both patients were maintained on cortisone acetate $37.5 \mathrm{mg}$. daily during the first month post-operatively. At one month the cortisone was completely withdrawn and an attempt made to estimate resting urinary corticosteroids.

Steroid Withdrawal.-In Case 1 symptoms of adrenal cortical insufficiency became apparent 24 hours after cortisone withdrawal. His temperature rose and apathy and weakness became marked. This was repeated on three separate occasions. Basal steroid estimations were subsequently obtained at one month and three months with the patient maintained on dexamethasone $0.5 \mathrm{mg}$. b.i.d. and $9 \alpha$-fluorohydrocortisone $0.1 \mathrm{mg}$. daily. Case 2 showed no sign of steroid lack when cortisone was withdrawn for one week. The blood-pressure remained constant on the same dose of guanethidine. Cortisone was again withdrawn four months after operation with the same results.

Adrenal Stimulation.-A.C.T.H. and metopirone stimulation tests were performed in both patients in the postoperative period. No changes in urinary steroids were observed. In Case 2 metopirone was continued for a further two days with the addition of dexamethasone $0.5 \mathrm{mg}$. b.i.d. On this regime there was no fall in the blood-pressure or change in the requirement of guanethidine.

Antibody Studies.-Complement-fixation tests with autoantigen and homoantigen were performed on blood removed from the first patient at $2,3,4 \frac{1}{2}$, and 8 months and from the second patient at 1,2 . and 4 months. Complement-fixing antibody was not detected in any sample.

\section{Discussion}

The outlook of patients with Cushing's syndrome has been substantially improved by subtotal and total adrenalectomy (Sprague et al., 1961). Recent descriptions of rapidly growing pituitary tumours following these operations (Siebennmann, 1955 ; Montgomery and Welbourn, 1957 ; Nelson et al., 1960) must, however, lead to a re-evaluation of this form of therapy. Most tumours were demonstrated before operation (Sprague et al., 1961) but others were not, and there seems little doubt that their increased growth is related to the adrenalectomy. Because of this, patients with adrenal hyperplasia who have evidence of pituitary tumour at the initial assessment are probably best treated by pituitary ablation. Refinements in techniques of pituitary implantation with radioactive seeds make this more easily achieved, and Joplin et al. (1961) have described their results in patients treated with yttrium-90 implantation.

Before this treatment can be recommended for a patient without obvious pituitary lesion it is important to exclude with certainty the possibility of adrenal neoplasm. The difficulties in achieving this are well illustrated in the two cases reported above. In the first patient, in whom an adrenal carcinoma was found, the history extended over at least 10 years. The 17-ketosteroid level was normal and the hypokalaemic alkalosis commonly seen with adrenal carcinoma was absent. In addition, despite the failure of dexamethasone to depress the high 17-hydroxysteroid output there was a

TABLE I.-Pre-operative Urinary Steroid Values (mg./24 Hours)

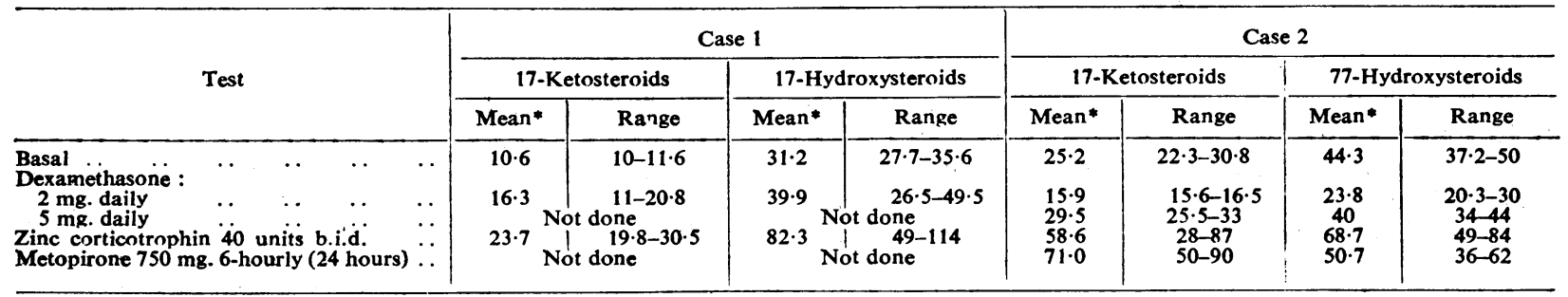

* Of 3 to 7 observations.

TABLE II.-Post-operative Urinary Steroid Values (mg./24 Hours)

\begin{tabular}{|c|c|c|c|c|c|c|c|c|c|}
\hline \multirow{3}{*}{$\begin{array}{l}\text { Time after } \\
\text { Operation }\end{array}$} & \multirow{3}{*}{ Test } & \multicolumn{4}{|c|}{ Case 1} & \multicolumn{4}{|c|}{ Case 2} \\
\hline & & \multicolumn{2}{|c|}{ 17-Ketosteroids } & \multicolumn{2}{|c|}{ 17-Hydroxysteroids } & \multicolumn{2}{|c|}{ 17-Ketosteroids } & \multicolumn{2}{|c|}{ 17-Hydroxysteroids } \\
\hline & & Mean* & Range & Mean * & Range & Mean * & Range & Mean* & Range \\
\hline $\begin{array}{l}1 \text { month } \\
1 \text { month } \\
6 \text { weeks } \\
6 \text { weeks }\end{array}$ & $\begin{array}{l}\text { Basal } \\
\text { Zinc corticotrophin } 40 \text { units b.i. } \ddot{d} . \\
\text { Basal } \\
\text { Metopirone } 750 \text { mg. } 6 \text { 6-hourly ( } 2 \ddot{4} \text { hours) }\end{array}$ & $\begin{array}{c}17 \cdot 8 \\
19 \cdot 4 \\
5 \cdot 3 \\
3 \cdot 7\end{array}$ & $\begin{array}{l}7 \cdot 5-25 \cdot 8 \\
22 \cdot 5-17 \\
3 \cdot 7-8 \cdot 9 \\
3 \cdot 1-4 \cdot 5\end{array}$ & $\begin{array}{l}5 \cdot 3 \\
6 \cdot 6 \\
5 \cdot 3 \\
4 \cdot 2\end{array}$ & $\begin{array}{l}2 \cdot 2-6 \cdot 7 \\
4 \cdot 3-8 \cdot 3 \\
3 \cdot 2-13 \cdot 1 \\
2 \cdot 5-6 \cdot 5\end{array}$ & $\begin{array}{c}4 \cdot 2 \\
3 \cdot 1 \\
11 \cdot 1 \\
11 \cdot 2\end{array}$ & $\begin{array}{l}3 \cdot 4-4 \cdot 8 \\
2 \cdot 8-3 \cdot 7 \\
6 \cdot 9-17 \cdot 2 \\
9 \cdot 5-14 \cdot 2\end{array}$ & $\begin{array}{l}9 \cdot 6 \\
7 \cdot 5 \\
8 \cdot 6 \\
9 \cdot 3\end{array}$ & $\begin{array}{l}9 \cdot 1-9 \cdot 9 \\
5 \cdot 4-9 \\
5 \cdot 1-11 \cdot 2 \\
7 \cdot 7-12 \cdot 3\end{array}$ \\
\hline
\end{tabular}


prompt and normal response to A.C.T.H. In the second patient, whose mother had died from unilateral adrenal carcinoma, presacral air insufflation suggested a unilateral tumour which proved to be a mass of fat. Similar errors in the interpretation of adrenal pneumograms have been reported by Iannoccone et al. (1960). The 17-ketosteroid excretion was high normal, and only moderate suppression of hydroxysteroids occurred during a course of dexamethasone $2 \mathrm{mg}$. daily, and not at all when the dose was increased to $5 \mathrm{mg}$. daily. Stimulation with A.C.T.H. increased the 17-hydroxysteroid level but not to the abnormally high values reported in adrenal hyperplasia (Birke et al., 1960). Metopirone produced a barely significant increase. The overall picture suggested an adrenal carcinoma, and this was supported by the relatively short clinical history.

These difficulties in the interpretation of biochemical data have been encountered by others (Nabarro et al., 1958).

Patients such as these, from whom tumour cannot be excluded with certainty, require exploration of the adrenal areas, with bilateral total adrenalectomy if hyperplasia is found. The disadvantage of total steroid dependence after the operation is considerable. Patients with Cushing's syndrome are on the whole difficult to manage; failure to co-operate or inability to obtain replacement drugs exposes them to the immediate danger of adrenal crisis. A procedure which minimized this risk, yet avoided a second major operation if there were a recurrence, would have obvious advantages. Franksson et al. (1956) showed that autografts of adrenal tissue could survive when implanted into the sartorius muscle direct or after rapid freezing with liquid nitrogen or air. They later performed adrenal autografts in five patients with adrenal hyperplasia who had had a total adrenalectomy (Franksson et al., 1959). Either one or both adrenals were implanted into the sartorius muscle of the respective sides, the tissue being easily accessible should there be a recurrence of the Cushing's syndrome. The glands were either implanted whole or divided into three or five portions.

In the cases reported above each gland was sectioned into fragments 1-2 mm. in thickness in order to increase the chances of the graft's survival (Brooks, 1961). The viability of the autograft also depends on a number of factors such as adequacy of blood supply and absence of local infection. In addition the formation of adrenal antibodies by an autoimmune process might lead to the destruction of implanted tissue. Such a mechanism has been postulated as the basis of adrenal atrophy in Addison's disease and complement-fixing antibodies have been demonstrated (Anderson et al., 1957). Steiner et al. (1960) produced widespread lesions in unilaterally adrenalectomized guinea-pigs receiving autologous adrenal tissue and concluded that the lesions were consistent with an autoimmune process. Despite the likelihood of escape of adrenal antigen into the circulation in the two cases described, no such antibodies were found.

The survival of grafted tissue in these two patients can only be inferred since the urinary steroids might equally well arise in residual accessory adrenal tissue (Cope and Raker, 1955). Franksson et al. (1959) demonstrated that this was not the case in one of their patients when removal of the adrenal autograft quickly led to signs of acute adrenal insufficiency. Such a procedure is not warranted in the present cases.
Since only a small portion of the grafted tissue may survive, it is important to implant as much adrenal gland as possible. In Case 1 only one gland was implanted. Although there was a significant excretion of 17 hydroxysteroids, the functioning tissue was inadequate for survival. Both glands were implanted in Case 2, and here the hydroxysteroid excretion was within normal limits. Adrenalectomized patients usually develop symptoms of steroid lack within $\mathbf{7 2}$ hours of cortisone withdrawal and seldom remain well beyond four days (Sim et al., 1961). Our patient remained well for at least one week after abrupt steroid withdrawal on two occasions. Franksson et al. (1959) showed that the capacity of the adrenal graft to secrete 17-hydroxysteroids improved with time, and this may be anticipated in these patients.

The complete lack of response to A.C.T.H. and metopirone stimulation in the post-operative period suggests maximal steroid secretion by the gland remnant. It seems likely that although the second patient can survive without cortisone replacement he will require supplements during periods of stress. It will be the aim of future grafting procedures to secure the survival of sufficient adrenal tissue to meet the requirements of both stress and everyday activities.

\section{Summary}

Two cases of Cushing's syndrome are described. Surgical exploration revealed adrenal carcinoma in one and bilateral adrenal hyperplasia in the other. The difficulties encountered in deciding the nature of the adrenal lesion before operation are discussed.

Total adrenalectomy was performed in both instances and the gland tissue implanted in the sartorius muscles. Significant excretion of 17-hydroxysteroids was demonstrated in the urine of both patients post-operatively and one patient remained well when cortisone was withdrawn.

Complement-fixing antibody to adrenal antigen could not be demonstrated in the blood of either patient in the post-operative period.

It is suggested that adrenal autografting should be attempted whenever total adrenalectomy is performed for Cushing's syndrome.

We thank Mr. D. Guthrie and Mr. K. N. MeNamara, senior and assistant surgeons, Auckland Hospital, who performed both operations. We are grateful to Dr. F. Sims who performed the steroid estimations, and to Mr. N. Fischmann, who carried out the antibody studies.

\section{REFERENCES}

Anderson, J. R., Goudie, R. B., Gray, K. G., and Timbury, G. C. (1957). Lancet, 1, 1123 .

Appleby, J. I., Gibson, G., Norymberski, J. K., and Stubbs, R. D. (1955). Biochem. J., 60, 453

Birke, G., Diczfalusy, E., and Plantin, L. O. (1960). J. clin. Endocr., 20, 593

Bishop, P." M.' F., de Mowbray, R. R., Glover, F. N., and Thorne, M. G. (1954). Lancet, 2, 1137.

Brooks, J. R. (1961). Ann. Rev. Med., 12, 271.

Cope, O., and Raker, J. W. (1955), New Engl. J. Med., 253, $119,165$.

Cushing. H. (1932). Bull. Johns Hopk. Hosp., 50, 137.

Drekter, J., Heisler, A., Scism, G., Stern, S., Pearson, S., and McGavack, T. (1952). J. clin. Endocr., 12, 55.

Franksson, C., Birke, G., Moberger, G., and Plantin, L. 0. (1956). Acta chir. scand., 111, 113

(1956). and Plantin. L. O. (1959). Ibid., 117, 409

Iannoccone, A.. Gabrilove, J. L., Brahms, S. A., and Soffer, L. J. (1960). Arch. intern. Med.. 105, 257.

Joplin, G. F. Fraser, R., Steiner, R., Laws, J., and Jones, E. (1961). Lancet. 2, 1277.

Lessof, M. H., and Bishop, P. M. F. (1956). Proc. roy. Soc. Med 49, 828 .

Luft, R. (1946), Acta med. scand., 124, 227. 
Montgomery, D. A. D., and Welbourn, R. B. (1957). Brit. J. Surg., 45, 137

Nabarro." J. D. N. Moxham, A., and Walker, G. (1958). J. clin. Endocr.. 18, 586.

Nelson, D. H., Meakin, S. W., and Thorn, G. W. (1960). Ann. intern. Med., 52, 560 .

Plotz, C. M., Knowlton, A. I., and Ragan, C. (1952). Amer. J. Med., 13, 597.

Siebennmann, R. E. (1955). Schweiz. Z. allg. Path., 18, 1189.

Sim, A. W., Hobkirk, R., Blair, D. W., Stewart, H. J., and Forrest, A. P. M. (1961). Lancet, 2, 73.

Skrimshire, J. F. P. (1955). Ibid., 1, 270

Sprague, R. G. (1953). Proc. roy. Soc. Med., 46, 1070

Weeks, R. E., Priestley, J. T., and Salassa, R. M. (1961) Modern Trends in Endocrinology, edited by $\mathrm{H}$. GardinerHill, p. 84. Butterworths, London

Steiner, J. W. Langer, B., Schatz, D. L., and Volpe, R. (1960). J. exp. Med., 112, 187.

$\overline{\underline{ }}$

\section{INDUCTION OF LABOUR BY INTRA- AMNIOTIC INJECTION OF HYPERTONIC GLUCOSE SOLUTION} BY

CARL WOOD, M.B., B.S., F.R.C.S., M.R.C.O.G. R. T. BOOTH, M.B.; B.S., M.R.C.O.G.

AND

JOHN H. M. PINKERTON, M.D., F.R.C.O.G.

From the Institute of Obstetrics and Gynaecology, Queen Charlotte's Hospital, London

Intrauterine death or foetal abnormality presents the obstetrician with a serious problem. Should he pursue a course of masterly inactivity, secure in the knowledge that at least he is doing no active physical harm to his potient ; or should he take steps to deliver her from her predicament as quickly as possible ?

On the whole immediate delivery, provided that it can be accomplished without undue risk to the mother, would seem preferable, and a safe reliable method of induction of labour in these cases would be a valuable addition to the armamentarium of the obstetrician. Intra-amniotic hypertonic solutions may provide such a method, and the preliminary trial of $50 \%$ glucose in water described below suggests that this is worthy of fuller investigation.

Brosset (1958) reported the successful induction of therapeutic abortion with $50 \%$ dextrose (usually followed by an intravenous drip of synthetic oxytocin) in 51 out of 54 patients between the 16th and 22nd weeks of pregnancy. He was " inclined to believe that a disturbance of the secretion of hormones of the ovum is brought about, the nature of which is still unknown " and this resulted in the expulsion of the products of conception.

Intrauterine hypertonic $20 \%$ saline was used successfully by Bengtsson and Csapo (1962) to induce therapeutic abortion in women between the 16th and 24th weeks of pregnancy. In a carefully planned series of experiments they produced evidence that the induction of labour by this procedure was due to diminished placental progesterone production. Although oxytocin alone (at infusion rates as high as 72 milliunits/minute for two consecutive days) did not terminate normal pregnancies between 16 and 24 weeks of gestation, a single intra-amniotic injection of $20 \%$ saline did so within 38 hours. They noted that after the intra-amniotic injection there was a marked fall in the blood and placental progesterone levels, while systemic progesterone given before the injection of the hypertonic saline delayed the onset of labour following this procedure from 31 to 68 hours. Also, progesterone has been shown to inhibit the propagation of the excitation wave in uterine muscle (Csapo, 1961).

In our series of late pregnancies (between the 28th and 40th weeks) glucose rather than saline was used because of the possible ill-effects to the mother of injecting approximately $40 \mathrm{~g}$. of sodium chloride into the uterus.

\section{Procedure}

There were 22 patients, including eight primigravidae ; 16 had intrauterine deaths of normally formed foetuses, and of the six congenital abnormalities two were live anencephalics (see Table).

Induction of Labour by Intra-amniotic Glucose in 22 Patients. Four Anencephalic Foetuses were Alive, All the Other Foetuses were dead at the time of induction

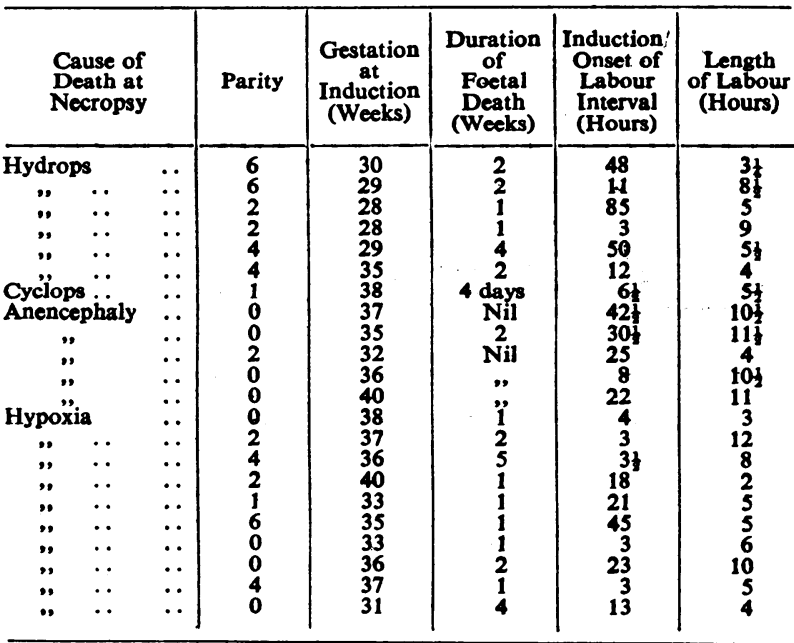

The patient emptied her bladder immediately before operation. After premedication local anaesthesia was induced with $0.5 \%$ procaine hydrochloride. A size 14 trocar and cannula was introduced into the uterus in the midline between the umbilicus and the symphysis pubis, taking care to avoid the upper edge of the bladder. The trocar was then removed and amniotic fluid flowing through the cannula showed that it was in the intra-amniotic space. In cases of foetal death the amniotic fluid is usually discoloured, often thick, and sometimes present in only very small amounts. A "polythene" catheter with an internal diameter of $1 \mathrm{~mm}$. and an external diameter of $2 \mathrm{~mm}$. was introduced into the amniotic cavity through the cannula, which was then removed. Amniotic fluid was first withdrawn, $200 \mathrm{ml}$. being removed where possible, and then $200 \mathrm{ml}$. of $50 \%$ glucose in water was injected through the polythene catheter, which was left in the uterus so that samples of amniotic fluid could be obtained for glucose-concentration estimations. Blood samples were also taken at regular intervals after the procedure was begun, for the same purpose.

In 12 patients the urinary excretion of oestrone, oestriol, oestradiol, and pregnanediol was measured. The intra-amniotic injection had to be repeated in two cases. In one the solution accidentally leaked out of the cannula and had to be replaced. In the other there was severe polyhydramnios and the injection of $250 \mathrm{ml}$. of $50 \%$ dextrose after the removal of some 3 litres of clear liquor under pressure failed to induce labour. The uterus was still very distended, and 48 hours later the procedure was repeated and another $250 \mathrm{ml}$. of $50 \%$ 